\title{
An inexpensive and efficient synthetic method for the preparation of pyromellitic dianhydride promoted by ionic liquid
}

\author{
Yu Lin Hu, Ming Lu,* Xiao Bin Liu, Sheng Bin Zhang, Zhan Hui Ji, and Ting Ting Lu \\ Chemical Engineering College, Nanjing University of Science and Technology, \\ Nanjing 210094, PR China \\ E-mail:_luming1963@163.com
}

\begin{abstract}
In this article, pyromellitic dianhydride could be successfully obtained in $76.7 \%$ total yield by an aerobic oxidation of 1,4-bis(chloromethyl)-2,5-dimethylbenzene or 1,5-bis(chloromethyl)-2,4dimethylbenzene catalyzed by $\mathrm{VO}(\mathrm{acac})_{2} / \mathrm{Cu}(2-\mathrm{Eth})_{2} / \mathrm{DABCO}$ in $[\mathrm{hmim}] \mathrm{OTf}$ and a subsequent dehydration of pyromellitic acid upon heating with acetic anhydride. The starting materials including 1,2-bis(chloromethyl)-4,5-dimethylbenzene were prepared by dichloromethylation of their corresponding xylene catalyzed by $\left[\mathrm{C}_{12} \mathrm{mim}\right] \mathrm{Br}$ in aqueous media.
\end{abstract}

Keywords: Pyromellitic dianhydride, ionic liquid, chloromethylation, oxidation, dehydration

\section{Introduction}

Pyromellitic dianhydride (PMDA) has been used extensively as an important monomer in the preparation of a variety of thermoplastics such as polyesters, polycarbonates, polyethers, plasticizers, expoxy resins, etc. Moreover, it is also useful in the preparation of high performance coatings that have been widely employed in many fields in our daily life beacuase of its excellent thermal, oxidative stability and excellent mechanical properties. ${ }^{1-6}$ Up to now, many publications in the open literature have been found in synthesis of production of pyromellitic dianhydride (PMDA), and the classical method for such a synthesis constitutes the liquid-phase oxidation of 1,2,4,5-tetraalkyl benzene catalyzed by cobalt, manganese, bromine, nitric acid or dichromic acid in the presence of 100-450 psig, and then dehydrating the obtained pyromellitic acid into pyromellitic dianhydride. ${ }^{7-10}$ However, this procedure is invariably associated with certain limitations such as high cost, long reaction time, environmental hazards, special apparatus and drastic reaction conditions. The catalytic vapor-phase oxidation of 1,2,4,5-tetraalkyl benzene under oxyen pressure using a certain catalyst (e.g. $\mathrm{V}_{3} \mathrm{O}_{5}-\mathrm{TiO}_{2}, \mathrm{WO}_{2}, \mathrm{~V}_{2} \mathrm{O}_{5}-\mathrm{TiO}_{2}$ ) is another 
well-known method, ${ }^{11-16}$ which, however, requires special equipment, low selectivity, use of stoichiometric and even excess amounts of reagents or catalysts, troublesome work-up procedures, etc. Other notable methods to accomplish this conversion include the liquid-phase oxidation of 1,2,4-tetraalkyl benzene, ${ }^{17,18}$ the catalytic vapor-phase oxidation of 1,2,4-tetraalkyl benzene, ${ }^{19-21}$ etc. $^{22,23}$ However, some of these procedures are invariably associated with one or more disadvantages such as high cost, long reaction time, complicated manufactures, special apparatus, etc. Consequently, there is a great need to develop an efficient procedure for the synthesis of pyromellitic dianhydride.

Ionic liquids (ILs) are a class of organic salts with unusually low melting temperatures that have attracted much attention from the scientific community in recent years. As a class of potential greener solvents, ILs exhibit many unique physicochemical properties, such as negligible volatility and nonflammability under ambient conditions, large liquid range, high thermal stability, wide electrochemical window, and strong ability to dissolve many chemicals. $^{24,27}$ Therefore, ILs have found wide applications in chemical synthesis, ${ }^{25-27}$ biocatalytic transformations, ${ }^{28,29}$ electrochemistry, ${ }^{30}$ and analytical and separation science. ${ }^{31,32}$

Molecular oxygen may serve as superior oxidant that exhibites lower cost, greater abundance, and improved safety contrast to other oxidizing reagents $\left(\mathrm{KMnO}_{4}, \mathrm{MnO}_{2}, \mathrm{CrO}_{3}\right.$, etc. $){ }^{33}$ Furthermore, the use of molecular oxygen as the primary oxidant may also have the advantage that water is the sole final byproduct. Thus, catalytic aerobic oxidation represents a promising protocol for organic synthesis and industrial applications. Accordingly, there has been concerted effort directed at developing various transition metals (copper, vanadium, palladium, etc.) ${ }^{34-37}$ to catalyze aerobic oxidation. Vanadyl acetylacetonate $\left(\mathrm{VO}(\mathrm{acac})_{2}\right)^{38-40}$ and copper (II) 2-ethylhexanoate $\left(\mathrm{Cu}(2-\mathrm{Eth})_{2}\right)^{41,42}$ have been extensively used in organic chemistry as reagents in the epoxidation of allylic alcohols, showing to be highly active, stereo- and regioselective catalysts. 1,4-diazabicyclo [2.2.2] octane (DABCO) is a highly efficient ligand and has been extensively applied in various organic reactions, such as Suzuki-Miyaura reaction, Baylis-Hillman reaction, epoxidation reaction, complexing ligand, etc. ${ }^{43-45}$

The objectives of the present work are to report an efficient and economic procedure for synthesis of pyromellitic dianhydride by aerobic oxidation reaction of bis(chloromethyl)xylenes 2a, 2b, 2c catalyzed by $\mathrm{VO}(\mathrm{acac})_{2} / \mathrm{Cu}(2-\mathrm{Eth})_{2} / \mathrm{DABCO}$ in [hmim]OTf and a subsequent dehydration of pyromellitic acid upon heating with acetic anhydride, and the starting materials were synthesized by chloromethylation of xylene using $\left[\mathrm{C}_{12} \mathrm{mim}\right] \mathrm{Br}$ as a catalyst in aqueous media (Scheme 1). 


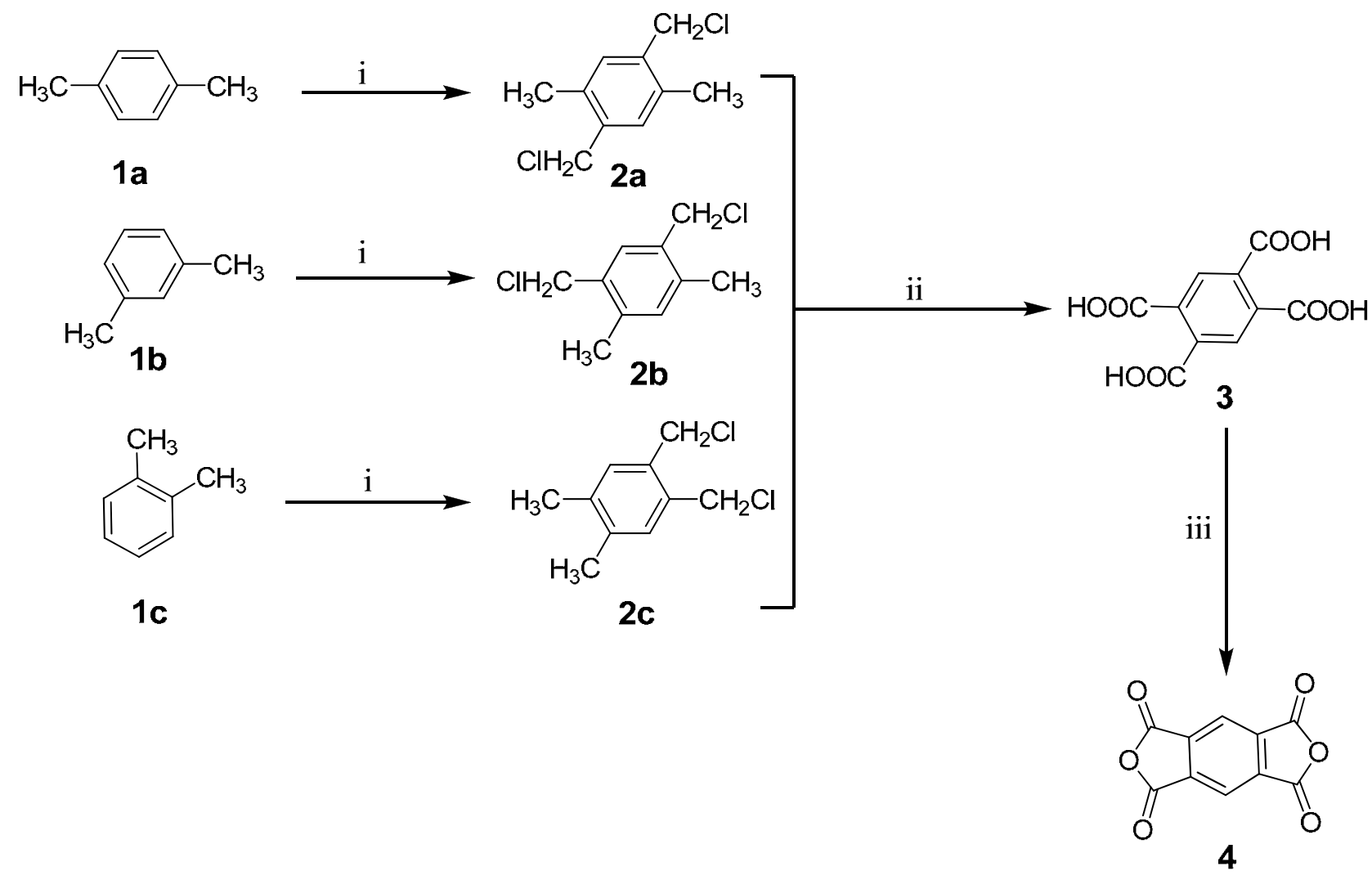

Reagents: (i) $\left(\mathrm{CH}_{2} \mathrm{O}\right)_{\mathrm{n}}, 50 \% \mathrm{H}_{2} \mathrm{SO}_{4}, \mathrm{AcOH},\left[\mathrm{C}_{12} \mathrm{mim}\right] \mathrm{Br}, \mathrm{HCl}, 55^{\circ} \mathrm{C}, 12 \mathrm{~h}$. (ii) $\mathrm{VO}(\mathrm{acac})_{2}$, $\mathrm{Cu}(2-\mathrm{Eth})_{2}, \mathrm{DABCO},[\mathrm{hmim}] \mathrm{OTf}, \mathrm{O}_{2}, 120^{\circ} \mathrm{C}, 24 \mathrm{~h}$. (iii) $\left(\mathrm{CH}_{3} \mathrm{CO}\right)_{2} \mathrm{O}$, reflux, $3 \mathrm{~h}$.

Scheme 1. Three-step synthesis of PMDA.

\section{Results and Discussion}

The dichloromethylation of $p$-xylene 1a was initially tested at $55^{\circ} \mathrm{C}$ in the presence and absence of 1-dodecyl-3-methylimidazolium bromide ([ $\left.\left.\mathrm{C}_{12} \mathrm{mim}\right] \mathrm{Br}\right)$. As shown in Table 1, in the absence of $\left[\mathrm{C}_{12} \mathrm{mim}\right] \mathrm{Br}$, the reaction proceeded very slowly, the yield was only $14 \%$ after $24 \mathrm{~h}$ (entry 1 ). Reaction performed with $\left[\mathrm{C}_{12} \mathrm{mim}\right] \mathrm{Br}$, it proceeded well, the yield increased to $37 \%$ in a shorter time (14 h) when only 0.02 equiv of [ $\left.\mathrm{C}_{12} \mathrm{mim}\right] \mathrm{Br}$ was used (Table 1 , entry 2 ). When the use of 0.09 equiv of the promoter, the desired reaction was efficiently carried out and the yield remarkablely increased to $82 \%$ in $12 \mathrm{~h}$ (Table 1 , entry 3 ). Thus, we can clearly observe that the yield increased with the increase in the amount of $\left[\mathrm{C}_{12} \mathrm{mim}\right] \mathrm{Br}$, and it reached maximum $(85 \%)$ when the 0.10 equiv of the promoter was used (Table 1, entry 4). However, further addition the amount of $\left[\mathrm{C}_{12} \mathrm{mim}\right] \mathrm{Br}$, under the same conditions, the yield was not enhanced significantly 
(Table 1, entries 5 and 6). These experiments revealed that $12 \mathrm{~h}$ and 0.10 equiv of the IL were necessary to complete the reaction. In addition, the IL could be typically recovered and reused with no appreciable decrease in yields and reaction rates (Table 1, entries 7 and 8). Besides $\left[\mathrm{C}_{12} \mathrm{mim}\right] \mathrm{Br}$, we also tried to use another types of ionic liquids such as 1-butyl-3-methylimidazolium bromide $\left(\left[\mathrm{C}_{4} \mathrm{mim}\right] \mathrm{Br}\right)$, 1-hexyl-3-methylimidazolium bromide $\left(\left[\mathrm{C}_{6} \mathrm{mim}\right] \mathrm{Br}\right)$, 1-methyl-3-octylimidazolium bromide $\left(\left[\mathrm{C}_{8} \mathrm{mim}\right] \mathrm{Br}\right)$ and 1-decyl-3-methylimidazolium bromide $\left[\mathrm{C}_{10} \mathrm{mim}\right] \mathrm{Br}$ as catalysts in the reaction (Table 1, entries 9-12), it was observed that $\left[\mathrm{C}_{12} \mathrm{mim}\right] \mathrm{Br}$ demonstrated the best performance. The experimental facts displayed distinctly the advantage of high efficiency of $\left[\mathrm{C}_{12} \mathrm{mim}\right] \mathrm{Br}$ catalysis. A review of the literature ${ }^{46}$ shows that ILs based on 1-alkyl-3-methylimidazolium cation $\left(\left[\mathrm{C}_{\mathrm{n}} \mathrm{mim}\right]^{+}\right)$possess inherent amphiphilic character when their alkyl group is a longer hydrocarbon chain, so the role of $\left[\mathrm{C}_{12} \mathrm{mim}\right] \mathrm{Br}$ in the reaction probably lies in the fact that it behaves like a classical surfactant and forms aggregates in water at low concentrations and self-assembles to form lyotropic mesophases at higher concentrations. When no surfactant $\left(\left[\mathrm{C}_{12} \mathrm{mim}\right] \mathrm{Br}\right)$ was used or surfactant concentration was below critical micelle concentration (CMC), the reaction system was a suspension (under stirring) with two phases, and the interface between oil phase and water phase was very small, so the reaction rate was very slow and a low yield was obtained, whilst the concentration was above CMC, the number of micelles increased with the increasing surfactant concentration (i.e. the amount of $\left[\mathrm{C}_{12} \mathrm{mim}\right] \mathrm{Br}$ increased), so the rate of chloromethylation speeded up and a higher yield could be obtained. The further increase of the surfactant concentration could induce micelles to expand, which could cause slow increase of oil/water interfacial area. Therefore, at high concentration, the rate increase became gradually slow and the yield did not change significantly. 
Table 1. Dichloromethylation of $p$-xylene catalyzed by ionic liquids in aqueous media ${ }^{a}$

\begin{tabular}{ccccc}
\hline Entry & Ionic liquid & $\begin{array}{c}\text { Ionic liquid } \\
\text { (equiv.) }\end{array}$ & Time $(\mathrm{h})$ & Yield (\%) $^{\mathrm{b}}$ \\
\hline 1 & {$\left[\mathrm{C}_{12} \mathrm{mim}\right] \mathrm{Br}$} & - & 24 & 14 \\
2 & {$\left[\mathrm{C}_{12} \mathrm{mim}\right] \mathrm{Br}$} & 0.02 & 14 & 37 \\
3 & {$\left[\mathrm{C}_{12} \mathrm{mim}\right] \mathrm{Br}$} & 0.09 & 12 & 82 \\
4 & {$\left[\mathrm{C}_{12} \mathrm{mim}\right] \mathrm{Br}$} & 0.10 & 12 & 85 \\
5 & {$\left[\mathrm{C}_{12} \mathrm{mim}\right] \mathrm{Br}$} & 0.11 & 12 & 85 \\
6 & {$\left[\mathrm{C}_{12} \mathrm{mim}\right] \mathrm{Br}$} & 0.13 & 12 & 85 \\
7 & {$\left[\mathrm{C}_{12} \mathrm{mim}\right] \mathrm{Br}$} & 0.10 & 12 & $85^{\mathrm{c}}$ \\
8 & {$\left[\mathrm{C}_{12} \mathrm{mim}\right] \mathrm{Br}$} & 0.10 & 12 & $84^{\mathrm{d}}$ \\
9 & {$\left[\mathrm{C}_{4} \mathrm{mim}\right] \mathrm{Br}$} & 0.10 & 12 & 37 \\
10 & {$\left[\mathrm{C}_{6} \mathrm{mim}\right] \mathrm{Br}$} & 0.10 & 12 & 61 \\
11 & {$\left[\mathrm{C}_{8} \mathrm{mim}\right] \mathrm{Br}$} & 0.10 & 12 & 70 \\
12 & {$\left[\mathrm{C}_{10} \mathrm{mim}\right] \mathrm{Br}$} & 0.10 & 12 & 79 \\
\hline
\end{tabular}

${ }^{a}$ Reaction conditions: 1a $(0.1 \mathrm{~mol})$, paraformaldehyde $(0.3 \mathrm{~mol}), 50 \% \mathrm{H}_{2} \mathrm{SO}_{4}(10 \mathrm{~mL})$, AcOH $(5$ $\mathrm{mL})$, anhydrous hydrogen chloride gas $(60 \mathrm{~mL} / \mathrm{min}), 55^{\circ} \mathrm{C}$. ${ }^{\mathrm{b}}$ Isolated yield. ${ }^{\mathrm{c}}$ The second run. ${ }^{\mathrm{d}}$ The third run.

With these results in hand, we subjected $m$-xylene $\mathbf{1 b}$ and $o$-xylene 1c to the optimized conditions, they were efficiently converted to the corresponding dichloromethyl-substituted products $\mathbf{2 b}$ and $\mathbf{2 c}$, and the yields were $86 \%$ and $65 \%$, respectively (Table 2 ). The yield of $\mathbf{2 c}$ was merely $65 \%$, becuase a mixture was obtained from the dichloromethylation of $1 \mathbf{c}$, the selectivity for 2c was only $78 \%$, which was confirmed by HPLC. 
Table 2. Dichloromethylation of $m$-xylene and $o$-xylene catalyzed by $\left[\mathrm{C}_{12} \mathrm{mim}\right] \mathrm{Br}$ in aqueous media $^{\mathrm{a}}$

\begin{tabular}{cccc}
\hline Substrate & Catalyst & Yield $(\%)^{\mathrm{b}}$ & ${\text { Selectivity }(\%)^{\mathrm{c}}}^{\mathrm{c}}$ \\
\hline$m$-xylene & {$\left[\mathrm{C}_{12} \mathrm{mim}\right] \mathrm{Br}$} & 86 & 100 \\
$o$-xylene & {$\left[\mathrm{C}_{12} \mathrm{mim}\right] \mathrm{Br}$} & 65 & 78 \\
\hline
\end{tabular}

${ }^{a}$ Reaction conditions: $\mathbf{1 b}$ or $1 \mathbf{1 c}(0.1 \mathrm{~mol})$, paraformaldehyde $(0.3 \mathrm{~mol}), 50 \% \mathrm{H}_{2} \mathrm{SO}_{4}(10 \mathrm{~mL})$, $\mathrm{AcOH}(5 \mathrm{~mL}),\left[\mathrm{C}_{12} \mathrm{mim}\right] \mathrm{Br}(0.01 \mathrm{~mol})$, anhydrous hydrogen chloride gas $(60 \mathrm{~mL} / \mathrm{min}), 55^{\circ} \mathrm{C}$, $12 \mathrm{~h}$.

${ }^{\mathrm{b}}$ Isolated yield.

${ }^{\mathrm{c} I s o l a t e d ~ s e l e c t i v i t y .}$

The aerobic oxidation of 1,4-bis(chloromethyl)-2,5-dimethylbenzene 2a was tested in the presence of DABCO at $120^{\circ} \mathrm{C}$, and the results are summarized in Table 3. No reaction occurred in the absence of $\mathrm{VO}(\mathrm{acac})_{2}$ (Table 3, entry 1) and very low yield of $\mathbf{3}$ was obtained (14\% yield after $48 \mathrm{~h}$ ) in the absence of $\mathrm{Cu}(2 \text {-Eth) })_{2}$ (Table 3 , entry 9). It can be observed that both $\mathrm{VO}(\mathrm{acac})_{2}$ and $\mathrm{Cu}(2-\mathrm{Eth})_{2}$ as catalysts are crucial for this reaction. Further efforts were then focused on optimizing the reaction medias for the oxidative process. At first, four types of ionic liquids, 1-hexyl-3-methylimidazolium trifluoromethansulfonate ([hmim]OTf), 1-butyl-1-methylpyrrolidini- um bis(trifluoromethylsulfonyl)imide ([bmpyr] $\mathrm{NTf}_{2}$ ), 1-butyl-3-methylimidazolium hexafluoroph- osphate $\left(\left[\mathrm{bmim}^{-} \mathrm{PF}_{6}\right), \quad\right.$ and 1-butyl-4-methylpyridinium hexafluorophosphate ([bmpy] $\mathrm{PF}_{6}$ ) were tested with $\mathrm{VO}(\mathrm{acac})_{2}$ and $\mathrm{Cu}(2-\mathrm{Eth})_{2}$ as the catalysts. It is clear that all the ionic liquids gave comparable isolated yields, and [hmim] OTf showed to be optimal (Table 3, entries 3-6). However, when in the case of entry 2 , the reaction did not proceed well, and the yield was only $18 \%$ after $48 \mathrm{~h}$. The experimental facts displayed distinctly the advantage of high efficiency of the reaction media [hmim]OTf. ILs are able to dissolve and stabilize the transition-metal catalyst precursors, ${ }^{47}$ thus providing an excellent support and medium for the aerobic oxidation, which may be explains why the yields when in the presence of ionic liquids as reaction medias were higher than that of not. The different effects of ILs in the reaction may be attributed to their different abilities of stabilizing and dissolving the transition-metal catalyst precursors and molecular oxygen. Under the same conditions, the IL who stabilizes and dissolves the transition-metal catalyst precursors and molecular oxygen more easily will leads to a larger increase in the effective reactant concentration, which increases the encounter probabilities between 2a and reactive species, and the higher rate and yield of the reaction is observed. Finally, we also tried to use another types of cocatalysts such as $\mathrm{Cu}(\mathrm{acac})_{2}$, $\mathrm{Cu}(\mathrm{OAc})_{2}$ and $\mathrm{Pb}(\mathrm{OAc})_{2}$ in the reaction, under the same conditions, however, the yields were merely $57 \%, 72 \%$ and $81 \%$, respectively (Table 3, entries 10-12). The best cocatalyst is $\mathrm{Cu}(2 \text {-Eth })_{2}$. Therefore, the optimal reaction conditions were observed in Table 3, entry 2. In 
addition, the catalytic system could be typically recovered and reused with no appreciable decrease in yields and reaction rates (Table 3, entries 7 and 8). With these results in hand, we subjected $\mathbf{2 b}$ and $\mathbf{2 c}$ to the optimized conditions, and high yields of $92 \%$ and $91 \%$ were obtained respectively.

Table 3. Aerobic oxidation of 1,4-bis(chloromethyl)-2,5-dimethylbenzene into pyromellitic acid in ionic liquids ${ }^{\mathrm{a}}$

\begin{tabular}{|c|c|c|c|c|c|}
\hline Entry & Catalyst & Cocatalyst & Ionic liquid & Time (h) & Yield $(\%)^{b}$ \\
\hline 1 & - & $\mathrm{Cu}(2-\mathrm{Eth})_{2}$ & {$[\mathrm{hmim}] \mathrm{OTf}$} & 48 & 0 \\
\hline 2 & $\mathrm{VO}(\mathrm{acac})_{2}$ & $\mathrm{Cu}(2-\mathrm{Eth})_{2}$ & - & 48 & 18 \\
\hline 3 & $\mathrm{VO}(\mathrm{acac})_{2}$ & $\mathrm{Cu}(2-\mathrm{Eth})_{2}$ & [hmim]OTf & 24 & 93 \\
\hline 4 & $\mathrm{VO}(\mathrm{acac})_{2}$ & $\mathrm{Cu}(2-\mathrm{Eth})_{2}$ & {$[\mathrm{bmpyr}] \mathrm{NTf}_{2}$} & 48 & 79 \\
\hline 5 & $\mathrm{VO}(\mathrm{acac})_{2}$ & $\mathrm{Cu}(2-\mathrm{Eth})_{2}$ & {$\left[\mathrm{bmim} \mathrm{PF}_{6}\right.$} & 48 & 51 \\
\hline 6 & $\mathrm{VO}(\mathrm{acac})_{2}$ & $\mathrm{Cu}(2-\mathrm{Eth})_{2}$ & [bmpy] $\mathrm{PF}_{6}$ & 48 & 27 \\
\hline 7 & $\mathrm{VO}(\mathrm{acac})_{2}$ & $\mathrm{Cu}(2 \text {-Eth })_{2}$ & {$[\mathrm{hmim}] \mathrm{OTf}$} & 24 & $93^{c}$ \\
\hline 8 & $\mathrm{VO}(\mathrm{acac})_{2}$ & $\mathrm{Cu}(2-\mathrm{Eth})_{2}$ & {$[\mathrm{hmim}] \mathrm{OTf}$} & 24 & $92^{\mathrm{d}}$ \\
\hline 9 & $\mathrm{VO}(\mathrm{acac}) 2$ & - & {$[\mathrm{hmim}] \mathrm{OTf}$} & 48 & 14 \\
\hline 10 & $\mathrm{VO}(\mathrm{acac}) 2$ & $\mathrm{Cu}(\mathrm{acac})_{2}$ & {$[\mathrm{hmim}] \mathrm{OTf}$} & 24 & 57 \\
\hline 11 & $\mathrm{VO}(\mathrm{acac}) 2$ & $\mathrm{Cu}(\mathrm{OAc})_{2}$ & {$[\mathrm{hmim}] \mathrm{OTf}$} & 24 & 72 \\
\hline 12 & $\mathrm{VO}(\mathrm{acac}) 2$ & $\mathrm{~Pb}(\mathrm{OAc})_{2}$ & [hmim]OTf & 24 & 81 \\
\hline
\end{tabular}

${ }^{\mathrm{a}}$ Reaction conditions: 2a $(0.05 \mathrm{~mol}), \mathrm{VO}(\mathrm{acac})_{2}(7 \mathrm{mmol}), \mathrm{DABCO}(13 \mathrm{mmol})$, cocatalyst (7 mmol), ionic liquid $(0.05 \mathrm{~mol}), 1 \mathrm{~atm} \mathrm{O}_{2}, 120{ }^{\circ} \mathrm{C}$.

${ }^{\mathrm{b}}$ Isolated yield.

${ }^{\mathrm{c}}$ The second run.

${ }^{\mathrm{d}}$ The third run.

During the process of dehydration, the acetic anhydride had great influences on the reaction, which is shown in Figure 1. No reaction occurred in the absence of acetic anhydride, and the increase in the amount of acetic anhydride (i.e. the ratio increased) enhanced the activity of 
dehydration. The yield reached maximum at 15.7 of the ratio. Further addition the amount of acetic anhydride, under the same conditions, the yield was not enhanced significantly.

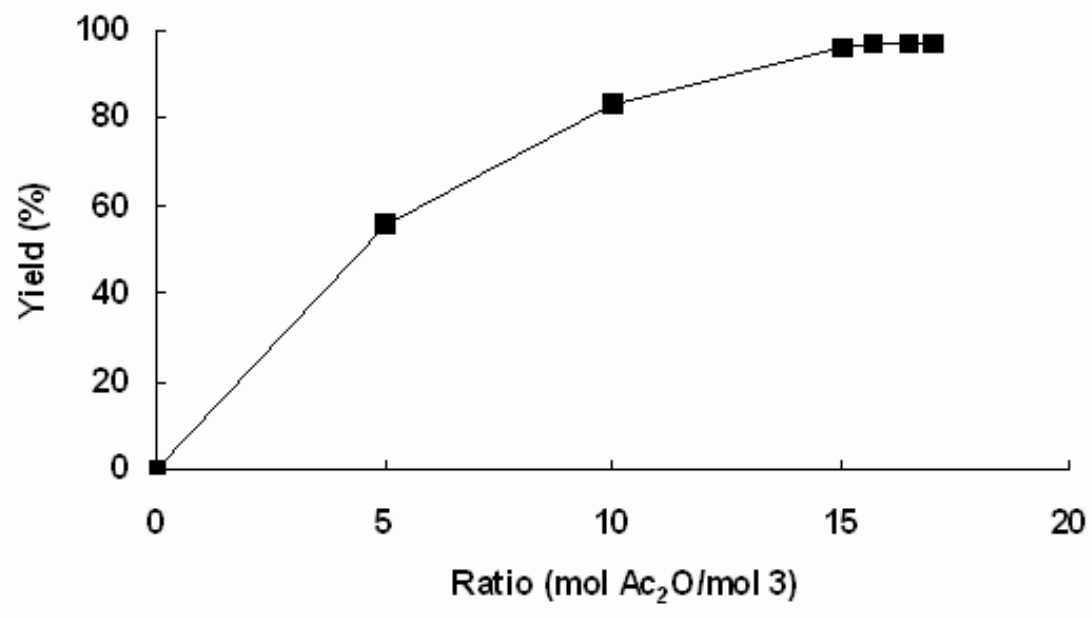

Figure 1. Influences of the amount of acetic anhydride on the dehydration. Reaction conditions: pyromellitic acid (0.05 mol), reflux, $3 \mathrm{~h}$.

\section{Conclusions}

In conclusion, we have developed an efficient synthetic pathway for the preparation of pyromellitic dianhydride starting from commercially available $p$-xylene or $m$-xylene in three steps. Compared to the synthetic methods reported in previous literature, ${ }^{7-23}$ not only was the yield of product greatly improved, but also the operating units were easy workup. One of the noticeable points in our paper was that the catalysts are easy to handle and could be recycled and reused without any significant loss of catalytic activity, and another glittery point was that the facile manipulations in the isolation of the products. Judging from the conditions employed, this method showed has great prospects in industrial applications.

\section{Experimental Section}

General. All the used chemicals were from commercial sources without any pretreatment. All reagents were of analytical grade. The ionic liquids were synthesized according to the literature 
procedures. ${ }^{48-50}$ The required substrates 2-4 were prepared according to the related methods. ${ }^{42,51,52}$ The target substrates were characterized by Elemental analysis, ${ }^{1} \mathrm{H}$ NMR, ${ }^{13} \mathrm{C}$ NMR or compared with their authentic samples. Melting points were determined on an electrothermal (Prolabo 9200) apparatus and are uncorrected. NMR spectra were recorded on a Bruker 400-MHz spectrometer. High performance liquid chromatography (HPLC) experiments were performed on a liquid chromatograph (Dionex Softron $\mathrm{GmbH}$, America), consisting of a pump (P680) and ultraviolet-visible light detector (UVD) system (170U). The experiments were performed on Diacovery C18 column, ø $4.6 \times 250 \mathrm{~mm}$. IR spectra were recorded on a Perkin Elmer PE-983 infrared spectrometer, as $\mathrm{KBr}$ pellets with absorption in $\mathrm{cm}^{-1}$. Elemental analysis were performed on a Vario EL III instrument (Elmentar Anlalysensy Teme GmbH, Germany).

\section{Preparation of bis(chloromethyl)xylene (2a, 2b, 2c) using $p$-xylene as an example}

A mixture of compound 1a (10.6 g, $0.1 \mathrm{~mol})$, paraformaldehyde $(9.0 \mathrm{~g}, 0.3 \mathrm{~mol})$, aqueous $\mathrm{H}_{2} \mathrm{SO}_{4}$ $(50 \%, 10 \mathrm{~mL}), \mathrm{AcOH} 5 \mathrm{~mL}$ and $\left[\mathrm{C}_{12} \mathrm{mim}\right] \mathrm{Br}(3.34 \mathrm{~g}, 0.01 \mathrm{~mol})$ were added in a $100 \mathrm{~mL}$ round flask equipped with reflux condenser and oil-bath. Anhydrous hydrogen chloride gas was bubbled into the flask at the flow rate of $60 \mathrm{~mL} / \mathrm{min}$. The reaction mixture was stirred for $12 \mathrm{~h}$ at $55^{\circ} \mathrm{C}$, the reaction progress was monitored by HPLC. After the reaction, the mixture was cooled and filtered and extracted with methylene chloride $(3 \times 20 \mathrm{~mL})$. The organic phases were combined and rinsed with $\mathrm{NaHCO}_{3}$ solution $(20 \%, 3 \times 20 \mathrm{~mL})$ and water $(3 \times 20 \mathrm{~mL})$, then dried over anhydrous $\mathrm{Na}_{2} \mathrm{SO}_{4}$. The solvent was evaporated and the crude product was recrystallized from hexane and methylene chloride afforded a white powder.

2a. 17.3 g, yield 85\%; m.p. 102-104 ${ }^{\circ} \mathrm{C}$; IR (KBr, cm $\left.{ }^{-1}\right): 2976$ (s), 2865 (m), 1637 (m), 1506 (s), 1454 (s), 1382 (m), 895 (s), 806 (s), 656 (vs); ${ }^{1} \mathrm{H} \mathrm{NMR} \mathrm{(400MHz,} \delta$ in ppm from TMS in $\left.\mathrm{CDCl}_{3}\right)$ : $2.34\left(\mathrm{~s}, 3 \mathrm{H}, \mathrm{CH}_{3}\right), 4.67\left(\mathrm{~s}, 2 \mathrm{H}, \mathrm{CH}_{2}\right), 7.16(\mathrm{~s}, 2 \mathrm{H}, \mathrm{Ar}-\mathrm{H}) ;{ }^{13} \mathrm{C} \mathrm{NMR}(400 \mathrm{MHz}, \delta$ in ppm from TMS in $\mathrm{CDCl}_{3}$ ): 17.8 (q), 40.7 (t), 131.2 (d), 133.7 (s), 138.3 (s). Anal. Calcd for $\mathrm{C}_{10} \mathrm{H}_{12} \mathrm{Cl}_{2}$ : C, 59.03; H, 5.98; Cl, 34.97. Found: C, 59.13; H, 5.96; Cl, 34.91.

2b. 17.5 g, yield 86\%; m.p. 88-90 ${ }^{\circ} \mathrm{C}$; IR ( $\left.\mathrm{KBr}, \mathrm{cm}^{-1}\right)$ : 2963 (s), 2869 (m), 1615 (m), 1512 (s), 1468 (s), 1384 (m), 902 (s), 808 (s), 658 (vs); ${ }^{1} \mathrm{H}$ NMR (400MHz, $\delta$ in ppm from TMS in $\left.\mathrm{CDCl}_{3}\right)$ : $2.37\left(\mathrm{~s}, 3 \mathrm{H}, \mathrm{CH}_{3}\right), 4.69\left(\mathrm{~s}, 2 \mathrm{H}, \mathrm{CH}_{2}\right), 7.04(\mathrm{~s}, 1 \mathrm{H}, \mathrm{Ar}-\mathrm{H}), 7.25(\mathrm{~s}, 1 \mathrm{H}, \mathrm{Ar}-\mathrm{H}) ;{ }^{13} \mathrm{C} \mathrm{NMR}(400 \mathrm{MHz}$, $\delta$ in ppm from TMS in $\mathrm{CDCl}_{3}$ ): 17.5 (q), 40.5 (t), 129.2 (d), 131.2 (d), 134.5 (s), 136.8 (s). Analysis Calcd for $\mathrm{C}_{10} \mathrm{H}_{12} \mathrm{Cl}_{2}$ : C, 59.09; H, 5.97; Cl, 34.94. Found: C, 59.13; H, 5.96; Cl, 34.91.

2c. 13.2 g, yield 65\%; m.p. 103-105 ${ }^{\circ} \mathrm{C}$; IR $\left(\mathrm{KBr}, \mathrm{cm}^{-1}\right)$ : 2972 (s), $2871(\mathrm{~m}), 1628(\mathrm{~m}), 1510$ (s), 1457 (s), 1381 (m), 910 (s), 807 (s), 661 (vs); ${ }^{1} \mathrm{H} \mathrm{NMR} \mathrm{(400MHz,} \delta$ in ppm from TMS in $\left.\mathrm{CDCl}_{3}\right)$ : $2.36\left(\mathrm{~s}, 3 \mathrm{H}, \mathrm{CH}_{3}\right), 4.70\left(\mathrm{~s}, 2 \mathrm{H}, \mathrm{CH}_{2}\right), 7.14(\mathrm{~s}, 2 \mathrm{H}, \mathrm{Ar}-\mathrm{H}) ;{ }^{13} \mathrm{C} \mathrm{NMR}(400 \mathrm{MHz}, \delta$ in ppm from TMS in $\mathrm{CDCl}_{3}$ ): 18.5 (q), 40.7 (t), 131.2 (d), 134.1 (s), 138.1 (s). Analysis Calcd for $\mathrm{C}_{10} \mathrm{H}_{12} \mathrm{Cl}_{2}$ : C, 59.07; H, 6.01; Cl, 34.92. Found: C, 59.13; H, 5.96; Cl, 34.91.

\section{Preparation of pyromellitic acid (3) using compound $2 \mathbf{a}$ as an example}

A mixture of compound 2a (10.1 g, $0.05 \mathrm{~mol}), \mathrm{VO}(\mathrm{acac})_{2}(1.86 \mathrm{~g}, 7 \mathrm{mmol}), \mathrm{Cu}(2-\mathrm{Eth})_{2}(2.45 \mathrm{~g}$, $7 \mathrm{mmol}), \mathrm{DABCO}(1.45 \mathrm{~g}, 13 \mathrm{mmol})$, and [hmim]OTf $(15.8 \mathrm{~g}, 0.05 \mathrm{~mol})$ were added in a $100 \mathrm{~mL}$ 
round flask equipped with reflux condenser and oil-bath. The round flask was capped with a rubber septum, and the reaction mixture was vigorously stirred at $120^{\circ} \mathrm{C}$ under $1 \mathrm{~atm} \mathrm{O}_{2}$ for $24 \mathrm{~h}$, the reaction progress was monitored by HPLC. After the reaction, the mixture was extracted with methylene chloride $(3 \times 20 \mathrm{~mL})$. The combined organic phases was concentrated in vacuo. The residue was recrystallized from distilled water afforded a white powder $11.8 \mathrm{~g}$, yield 93\%. m.p. 272-274 ${ }^{\circ} \mathrm{C} ;{ }^{1} \mathrm{H}$ NMR $\left(400 \mathrm{MHz}, \delta\right.$ in ppm from TMS in DMSO- $\left.d_{6}\right): 7.83$ (s, $\left.2 \mathrm{H}, \mathrm{Ar}-\mathrm{H}\right), 12.2-13.3$ (br s, $4 \mathrm{H}, \mathrm{COOH}) ;{ }^{13} \mathrm{C}$ NMR $\left(400 \mathrm{MHz}, \delta\right.$ in ppm from TMS in DMSO- $\left.d_{6}\right): 129.4$ (d), 136.7 (s), 167.9 (s). Analysis Calcd for $\mathrm{C}_{10} \mathrm{H}_{6} \mathrm{O}_{8}: \mathrm{C}, 47.31 ; \mathrm{H}, 2.40 ; \mathrm{O}, 50.32$. Found: C, 47.26; H, 2.38; O, 50.36 .

\section{Preparation of PMDA (4)}

In a $250 \mathrm{~mL}$ round flask, compound $3(12.7 \mathrm{~g}, 0.05 \mathrm{~mol})$ was added to the stirred solution containing acetic anhydride $(80 \mathrm{~mL}, 0.784 \mathrm{~mol})$. The suspension was gradually heated to reflux for $3 \mathrm{~h}$, the reaction progress was monitored by HPLC. After the reaction, the mixture was cooled, the precipitate was filtered off, dried in vacuum, afford a white powder $10.6 \mathrm{~g}$, yield 97\%. m.p. 283-285 ${ }^{\circ} \mathrm{C}$ (lit. ${ }^{17}$ m.p. $281-284{ }^{\circ} \mathrm{C}$ ); ${ }^{1} \mathrm{H}$ NMR $(400 \mathrm{MHz}, \delta$ in ppm from TMS in DMSO-d 6 ): 8.72 (s, 2H, Ar-H); ${ }^{13} \mathrm{C}$ NMR (400MHz, $\delta$ in ppm from TMS in DMSO-d $\left.d_{6}\right): 124.2$ (d), $137.3(\mathrm{~s}), 162.7$ (s). Analysis Calcd for $\mathrm{C}_{10} \mathrm{H}_{2} \mathrm{O}_{6}: \mathrm{C}, 55.07 ; \mathrm{H}, 0.89 ; \mathrm{O}, 44.03$. Found: $\mathrm{C}, 55.06 ; \mathrm{H}, 0.92 ; \mathrm{O}, 44.01$.

\section{Acknowledgments}

We thank National Basic Research Program (973) of China and Ministry of Education of China for support of this research. The authors would also like to express their thanks to Prof. Dr. Qing Wei Hang of Nanjing University for ${ }^{13} \mathrm{C}$ DEPT NMR experimental assistance and helpful suggestions.

\section{References}

1. Ding, M. X.; He, T. B. Polyimide Material; Chemical Industry Press: Beijing, 1998; pp 283294.

2. Sroog, C. E.; Endrey, A. L.; Abramo, S. V.; Berr, C. E.; Edwards, W. M.; Olivier, K. L. J. Polym. Sci., Part A 1965, 3, 1373.

3. David, R. B.; John, C. B. Inorg. Chem. 1972, 11, 1578.

4. Gong, J. H.; Lin, J.; Liu, X. Y. Chin. J. Ind. Med. 1997, 10, 186.

5. Masahiro, T.; Takahiro, H.; Hiroyuki, O. Tetrahedron Lett. 2007, 48, 1553.

6. Ding, Z. P.; Yang, X. D.; Zhu, Z. Q. Chin. J. Chem. Ind. Eng. Process 2006, 25, 1443. 
7. Ai, M.; Suzuki, S. Bull. Chem. Soc. Jap.1974, 47, 3074.

8. Masayoshi, I.; Hideshi, H.; Kozo, T. J. Catal. 1974, 35, 225.

9. Tanabe, K.; Sumiyoshi, T.; Shibata, K. Bull. Chem. Soc. Jap.1974, 47, 1064.

10. Hirai, K.; Misonoo, T.; Abe, Y. J.P. Patent 6,127,942, 1994.

11. Maeda, M.; Kodama, Y. U.S. Patent 4,847,010, 1989.

12. Maeda, M.; Yamada, Y. U.S. Patent 5,387,669, 1995.

13. Chu, S. J.; Chu, H.; Hwang, C. L.; Hsiung, K. U.S. Patent 6,084,109, 2000.

14. Toshio, S.; Tsukasa, T.; Yasuhisa, E. U.S. Patent 6,153,767, 2000.

15. Masaaki, O.; Hiromi, Y.; Yasushi, K.; Daisuke, N.; Michio, T. U.S. Patent 6344 568, 2002.

16. Takahashi, T.; Uhara, H.; Anyouji, K.; Matsunami, E. U.S. Patent 6699 999, 2003.

17. Tanaka, S.; Kurimoto, I.; Ishii, T.; Nakanishi, Y. J.P. Patent 62,027,043, 1987.

18. Xue, J. W.; Wu, L.; Lu, Z. P.; Li, F. X.; Dou, T. Chin. J. Fuel Chem. Technol. 2000, 28, 16.

19. Cao, L. H.; Ye, X. F. CN Patent 201,032,437, 2008.

20. Enomoto Norihide Technical Res; Naruse Yoshihiro Technical Res. E.P. Patent 0,330,195, 1989.

21. Wachs, I. E.; Chen, Y. S.; Briand, L. E. Catal. Today 2003, 78, 13.

22. Wu, W.; Guo, M. F. Chem. Adhesion 2002, 3, 173.

23. Dellacoletta, B.; Odle, R. R.; Guggenheim, T. K. U.S. Patent 5,936,099, 1999.

24. Saravanababu, M.; Robert, J. L. Curr. Org. Synth. 2005, 2, 437.

25. Dupont, J.; de Souza, R. F.; Suarez, P. A. Z. Chem. Rev. 2002, 102, 3667.

26. Wasserschein, P.; Welton, T. Ionic Liquids in Synthesis; Wiley-VCH: Weinhein, Germany, 2003.

27. Martins, M. A. P.; Frizzo, C. P.; Moreira, D. N.; Zanatta, N.; Bonacorso, H. G. Chem. Rev. 2008, 108, 2015.

28. Legeay, J. C.; Eynde, J. J. V.; Toupet, L.; Bazureau, J. P. Arkivoc 2007, (iii), 13.

29. Hajipour, A. R.; Khazdooz, L.; Ruoho, A. E. Catal. Commun. 2008, 9, 89.

30. Balducci, A.; Henderson, W. A.; Mastragostino, M.; Passerini, S.; Simon, P.; Soavi, F. Electrochim. Acta 2005, 50, 2233.

31. Dubois, P.; Marchand, G.; Fouillet, Y.; Berthier, J.; Douki, T.; Hassine, F.; Gmouh, S.; Vaultier, M. Anal. Chem. 2006, 78, 4909.

32. Zheng, J.; Row, K. H. Am. J. Appl. Sci. 2006, 3, 2160

33. March, J. Advanced Organic Chemistry: Reactions, Mechanisms, and Structure, 4th Edn.; John Wiley \& Sons: New York, 1992.

34. Steinhoff, B. A.; Fix, S. A.; Stahl, S. S. J. Am. Chem. Soc. 2002, 124, 766.

35. Vasylyev, M.; Neumann, R. Chem. Mater. 2006, 18, 2781.

36. Hou, Z.; Theyseeen, N.; Leitner, W. Green Chem. 2007, 9, 127.

37. Michael, D.; Helene, L. Org. Lett. 2009, 11, 41.

38. Ligtenbarg, A. G. J.; Hage, R.; Feringa, B. L. Coord. Chem. Rev. 2003, 237, 89.

39. Reddy, S. R.; Das, S.; Punniyamurthy, T. Tetrahedron Lett. 2004, 45, 3561.

40. Radosevich, A. T.; Musich, C.; Toste, F. D. J. Am. Chem. Soc. 2005, 127, 1090. 
41. Bekkum, H.; Lichtenthaler, F. W. Carbohydrates as Organic Raw Meterials; Wiley-VCH: Weinheim, 1990.

42. Jiang, N.; Ragauskas, A. J. J. Org. Chem. 2007, 72, 7030.

43. Li, J. H.; Liu, W. J. Xie, Y. X. J. Org. Chem. 2005, 70, 5409.

44. Shi, Y. L.; Shi, M. Org. Biomol. Chem. 2005, 3, 1620.

45. Jiang, N.; Ragauskas, A. J. Tetrahedron Lett. 2007, 48, 273.

46. Wang, J.; Wang, H.; Zhang, S.; Zhang, H.; Zhao, Y. J. Phys. Chem. B 2007, 111, 6181.

47. Ansari, I. A.; Gree, R. Org. Lett. 2002, 4, 1507.

48. Dzyuba, S.V.; Bartsch, R.A. J. Heterocyclic Chem. 2001, 38, 265.

49. Galan, M. C.; Brunet, C.; Fuensanta, M. Tetrahedron Lett. 2009, 50, 442.

50. Fang, Y. X.; Deng, Y. Q.; Ren, Q. G.; Huang, J. P. Chin. J. Chem. Eng. 2008, 16, 357.

51. Kenneth, R. S.; Annegret, S. Green Chem. 2002, 4, 119.

52. Yi, S.X.; Men, J.; Ma, X. Y.; Jiang, Y.; Gao, G. W. Chin. Chem. Lett. 2009, 20, 306. 